\title{
Correction to: Investigation of electronic environments and electrical characterization of functionalised AgNPs synthesized by electroless process
}

\author{
Rabina Bhujel ${ }^{1} \cdot$ Bibhu P. Swain ${ }^{2}$ (I)
}

Published online: 9 August 2019

(c) Springer-Verlag GmbH Germany, part of Springer Nature 2019

\section{Correction to: Applied Physics A (2019) 125:565 https://doi.org/10.1007/s00339-019-2864-6}

The author recently found a mistake in the abstract of his published paper.

The line:

"The area ratios for the two spin-orbit peaks for $\operatorname{IAg}\left(2 \mathrm{p}_{3 / 2}\right) / \operatorname{Iag}\left(2 \mathrm{p}_{1 / 2}\right)$ and $\operatorname{IAg}(3 \mathrm{~d})_{5 / 2} / \operatorname{IAg}(3 \mathrm{~d})_{3 / 2}$ are varied increasing from 1.95 to 1.54 and 1.92 to 2.8 , respectively, indicated modified coordination of $\mathrm{AgNPs}$ with $\mathrm{AgNO}_{3}$ concentrations."

Should be changed to:
"The area ratios for the two spin-orbit peaks for $\operatorname{IAg}\left(2 \mathrm{p}_{3 / 2}\right) / \operatorname{Iag}\left(2 \mathrm{p}_{1 / 2}\right)$ and $\operatorname{IAg}(3 \mathrm{~d})_{5 / 2} / \operatorname{IAg}(3 \mathrm{~d})_{3 / 2}$ are varied from 1.95 to 1.54 and 1.92 to 2.8 , respectively, indicated modified coordination of $\mathrm{AgNPs}$ with $\mathrm{AgNO}_{3}$ concentrations."

The original article has been corrected.

We apologize for this mistake.

Publisher's Note Springer Nature remains neutral with regard to jurisdictional claims in published maps and institutional affiliations.

The original article can be found online at https://doi.org/10.1007/ s00339-019-2864-6.

Bibhu P. Swain

bibhuprasad.swain@gmail.com; bpswain@nitmanipur.ac.in

1 Nanoprocessing Laboratory, Centre for Materials Science and Nanotechnology, Sikkim Manipal Institute of Technology, Sikkim Manipal University, Majitar, India

2 Department of Physics, National Institute of Technology Manipur, Imphal, Manipur 795004, India 